\title{
SnRK1 and TOR: modulating growth-defense trade-offs in plant stress responses
}

\author{
Leonor Margalha*, ${ }^{*}$, Ana Confraria ${ }^{\star,}$ and Elena Baena-González ${ }^{\dagger,(D)}$ \\ Instituto Gulbenkian de Ciência, Rua da Quinta Grande 6, 2780-156 Oeiras, Portugal \\ *These authors contributed equally to this work. \\ ${ }^{\dagger}$ Correspondence: ebaena@igc.gulbenkian.pt
}

Received 15 November 2018; Editorial decision 7 February 2019; Accepted 7 February 2019

Editor: Christian Meyer, INRA, UK

\begin{abstract}
The evolutionarily conserved protein kinase complexes SnRK1 and TOR are central metabolic regulators essential for plant growth, development, and stress responses. They are activated by opposite signals, and the outcome of their activation is, in global terms, antagonistic. Similarly to their yeast and animal counterparts, SnRK1 is activated by the energy deficit often associated with stress to restore homeostasis, while TOR is activated in nutrient-rich conditions to promote growth. Recent evidence suggests that SnRK1 represses TOR in plants, revealing evolutionary conservation also in their crosstalk. Given their importance for integrating environmental information into growth and developmental programs, these signaling pathways hold great promise for reducing the growth penalties caused by stress. Here we review the literature connecting SnRK1 and TOR to plant stress responses. Although SnRK1 and TOR emerge mostly as positive regulators of defense and growth, respectively, the outcome of their activities in plant growth and performance is not always straightforward. Manipulation of both pathways under similar experimental setups, as well as further biochemical and genetic analyses of their molecular and functional interaction, is essential to fully understand the mechanisms through which these two metabolic pathways contribute to stress responses, growth, and development.
\end{abstract}

Keywords: Defense, growth, plant, SnRK1, stress responses,TOR.

\section{Introduction}

Environmental stresses such as extreme temperatures, drought, flooding, or attacks from various pathogens are major yieldlimiting factors, reducing crop productivity by $>50 \%$ (Bray et al., 2000), and thereby our capacity to provide sufficient food, fiber, and fuel for a growing human population. To cope with adverse environmental conditions, plants trigger responses that range from rapid protective mechanisms (e.g. osmolyte accumulation) to developmental modifications (e.g. reduction in the shoot:root ratio), ultimately promoting stress tolerance and survival at the expense of growth. However, despite our increasing knowledge on stress responses, how stress impinges on growth is still poorly understood. Growth-defense tradeoffs may arise indirectly from nutrient reallocation and limitation during stress, but also as a direct output of the interplay between antagonistic signaling pathways that either promote or restrict growth (Huot et al., 2014; Eichmann and Schafer, 2015). A deep understanding of the interactions between stress and growth regulatory pathways is therefore essential to uncouple the two processes, making the two features compatible in plant breeding and engineering strategies. 
In plants, there are two central nutrient-sensing kinases with increasing connections to stress responses and growth, and with largely antagonistic functions: the protein kinase complexes SnRK1 (Snf1-related protein kinase 1) and TOR (target of rapamycin) (Broeckx et al., 2016; Dobrenel et al., 2016a; Margalha et al., 2016; Baena-Gonzalez and Hanson, 2017; Shi et al., 2018). SnRK1 is activated under low carbon conditions to promote energy-saving and nutrient remobilization strategies, whilst TOR is activated in response to nutrient availability to promote cell proliferation and growth. Despite having evolved numerous plant-specific features, these two eukaryotic complexes are to a large extent structurally and functionally conserved (Roustan et al., 2016). The SnRK1 and TOR pathways have been mostly studied independently and, despite an increasing interest, knowledge of their interconnections remains scarce. The answers to fundamental questions concerning their mutual regulation, as well as the mechanistic details behind commonly regulated processes, are still to be discovered.

In this review, we aim to cover the literature that addresses the connections between SnRK1 and TOR in plants, establishing analogies with other eukaryotic systems, when pertinent. Following a brief overview of SnRK1 and TOR in plants, we will focus on the involvement of these central pathways in the growth-defense trade-offs that are typically associated with biotic and abiotic stress responses (see Supplementary Table S1 at JXB online). It is important to note that these complexes also play roles throughout development (Baena-Gonzalez and Hanson, 2017), but these functions are beyond the scope of this review and will not be addressed here.

\section{SnRK1 and TOR in plants}

\section{Complex composition}

Arabidopsis SnRK1 is the closest relative of yeast SNF1 (sucrose non-fermenting 1) and animal AMPK (AMPactivated protein kinase), whereas SnRK2s and SnRK3s comprise more divergent plant-specific protein kinases of the SnRK superfamily (Hrabak et al., 2003; Crozet et al., 2014). SNF1/AMPK/SnRK1 are heterotrimeric serine-threonine protein kinase complexes, composed of an $\alpha$ catalytic subunit and two regulatory subunits, $\beta$ and $\gamma$. Three genes encode the $\alpha$ subunit in Arabidopsis, $\operatorname{SnRK} 1 \alpha 1, \operatorname{SnRK} 1 \alpha 2$, and $\operatorname{SnRK} 1 \alpha 3$ (also referred to as AKIN10/AKIN11/AKIN12 or KIN10/ KIN11/KIN12). SnRK1 $\alpha 1$ accounts for the majority of SnRK1 activity (Jossier et al., 2009), while SnRK1a3 is only expressed at low levels in pollen and seeds (Baena-Gonzalez et al., 2007; Winter et al., 2007; Fragoso et al., 2009). The $\beta$ subunit, which acts as a scaffold within the complex, is also

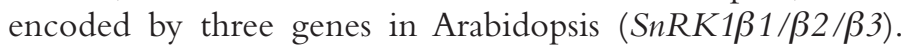
Amongst these, SnRK1 $\beta 3$ has plant-specific features, lacking the otherwise conserved $\mathrm{N}$-terminal extension domain, associated with subcellular localization and target specificity, and the carbohydrate-binding module (CBM) that in SNF1 and AMPK binds glycogen (Wiatrowski et al., 2004; Bendayan et al., 2009; McBride et al., 2009). Finally, the canonical regulatory $\gamma$ subunit is encoded by a single $\operatorname{SnRK1} \beta \gamma$ gene in
Arabidopsis (Kleinow et al., 2000; Lumbreras et al., 2001; Ramon et al., 2013; Emanuelle et al., 2015). SnRK1 $\beta \gamma$ has the characteristics of typical $\gamma$ subunits, such as a $\beta$-interacting sequence domain, and cystathionine- $\beta$-synthase domains that in AMPK $\gamma$ bind adenylates and allow allosteric activation by AMP (Crozet et al., 2014; Broeckx et al., 2016; Margalha et al., 2016). In addition, SnRK1 $\beta \gamma$ has plant-specific features, harboring a CBM on its N-terminus (Lumbreras et al., 2001; Ramon et al., 2013; Emanuelle et al., 2015). With the exception of $\operatorname{SnR} K 1 \beta \gamma$, for which null mutants are unviable (Ramon et al., 2013; Gao et al., 2016), all single mutants described for each of the subunits display a mostly wild-type phenotype under optimal growth conditions ( $\mathrm{Li}$ et al., 2009; Sheen, 2014; Jeong et al., 2015; Mair et al., 2015). This suggests at least partial redundancy amongst each type of subunit, and opens up the possibility that SnRK1 complexes exist in multiple forms depending on the combinations of subunits they harbor. Highlighting the centrality of this pathway, and similarly to snrk $1 \beta \gamma$, snrk $1 \alpha 1 / \alpha 2$ double knockouts in higher plants are unviable (Baena-Gonzalez et al., 2007).

The conserved TOR kinase belongs to the phosphatidylinositol 3-kinase-related protein kinase family. It also assembles into multiprotein complexes that in yeast and animals are of two types: TORC1 and TORC2 (TOR complex 1 and 2). Both types of complexes contain TOR kinase and LST8 (lethal with SEC thirteen protein 8), but differ in the associated regulatory subunits. TORC1 contains RAPTOR (regulatory associated protein of TOR), whereas TORC2 contains RICTOR (rapamycin-insensitive companion of TOR) and SIN1 (SAPK-interacting protein 1) (Saxton and Sabatini, 2017). However, in plants, there is only evidence for the existence of TORC1 complexes (van Dam et al., 2011). In the Arabidopsis genome, there is a single gene for the TOR kinase, which is highly expressed in young proliferating tissues, such as the embryo and the primary meristems (Menand et al., 2002). The other two TORC1 components, RAPTOR (Anderson et al., 2005; Deprost et al., 2005) and LST8 (Moreau et al., 2012), are encoded by two genes each, one of which is predominantly expressed (RAPTOR1B and LST8-1), with their corresponding single mutants displaying TOR-associated defects (Anderson et al., 2005; Deprost et al., 2005; Moreau et al., 2012; Salem et al., 2018). Similarly to snrk1 $\alpha 1 / \alpha 2$ and snrk1 $\beta \gamma$ knockouts, Arabidopsis tor null mutants are lethal (Menand et al., 2002; Ren et al., 2011).

\section{Mechanisms of activation}

SNF1/AMPK/SnRK1 are activated in response to declining energy levels. Whilst mammalian AMPK is activated in response to high AMP:ATP or ADP:ATP ratios, the ultimate signal that results in SnRK1 activation remains unknown (Margalha et al., 2016). Nevertheless, it is clear that SnRK1, unlike AMPK, is not allosterically activated by AMP (Wilson et al., 1996; Emanuelle et al., 2015), but its activity correlates with situations of energy deficit (Baena-Gonzalez et al., 2007; Baena-Gonzalez and Sheen, 2008; Tome et al., 2014). Conversely, sugar supply inactivates SnRK1 (Baena-Gonzalez et al., 2007; Baena-Gonzalez and Sheen, 2008) and this requires 
type 2C protein phosphatases (PP2Cs) in adult rosette leaves (Rodrigues et al., 2013). In actively growing young tissues, SnRK1 activity is inhibited indirectly by specific sugars such as trehalose-6-phosphate (T6P), glucose-6-phosphate, or glucose-1-phosphate (Toroser et al., 2000; Zhang et al., 2009; Nunes et al., 2013b). T6P is of particular relevance, as it has been ascribed a crucial role in sugar signaling (Schluepmann and Paul, 2009), functioning as a proxy of the plant sucrose status (Lunn et al., 2014). Recent data suggest that T6P inhibits SnRK1 by disrupting the interaction between SnRK1 and its upstream kinases SnAKs (Zhai et al., 2018) [SnRK1-activating kinases, also called GRIKs, geminivirus Rep-interacting kinases (Shen et al., 2009; Crozet et al., 2010)]. SnAKs phosphorylate SnRK1 on a conserved residue within the T-loop, the phosphorylation of which is required for SnRK1 kinase activity (Baena-Gonzalez et al., 2007). In vitro studies showed that SnRK1 activity and T-loop phosphorylation are regulated in response to the redox status, decreasing progressively in oxidizing conditions. This was attributed to the oxidation of a conserved Cys residue, situated in close proximity to the residue phosphorylated by SnAKs, also affected by oxidation themselves (Wurzinger et al., 2017). However, the in vivo evidence correlating T-loop phosphorylation with activation of SnRK1 signaling is controversial. T-loop phosphorylation was shown to increase in response to submergence (Cho et al., 2016), but other studies have reported similar levels of T-loop phosphorylation under control and stress conditions, raising the question of how SnRK1 activation occurs (Baena-Gonzalez et al., 2007; Fragoso et al., 2009; Coello et al., 2012; Rodrigues et al., 2013). This contrasts with SNF1 and AMPK, where there is a clear correlation between activity and phosphorylation of the conserved residue in the T-loop of the catalytic subunit (Kurumbail and Calabrese, 2016; Sanz et al., 2016).

In contrast to SNF1/AMPK/SnRK1, TOR is activated in nutrient-rich conditions. Surprisingly, some canonical upstream regulators of TORC1 in yeast and mammals are absent in plants (van Dam et al., 2011; Roustan et al., 2016), suggesting a diversification of the mechanisms conveying nutrient and energy signals to TOR in photoautotrophic organisms (Xiong and Sheen, 2015). In plants, photosynthesisderived glucose and sucrose were disclosed as potent activators ofTOR signaling in the root and shoot meristem (Xiong et al., 2013; Li et al.,2017).TOR is also activated by light in the shoot apical meristem, through the action of the growth hormone auxin (Pfeiffer et al., 2016; Li et al., 2017). Auxin activates TOR in both shoots and roots, presumably through a direct interaction and activation of TOR by the small GTPase Rho-related protein 2 (ROP2) (Schepetilnikov et al., 2013, 2017; Li et al., 2017). Interestingly, ROP 2 cannot be activated by glucose and is not able to replace glucose for TOR activation, indicating that TOR senses sugars either directly or through another upstream regulator (Li et al., 2017).

\section{Modes of action}

Downstream of SNF1/AMPK/SnRK1 activation, an energysaving program is launched through direct regulation of key metabolic enzymes and via transcriptional and translational regulation. In plants, SnRK1 phosphorylates and inactivates key metabolic enzymes of isoprenoid biosynthesis (3-hydroxy3-methylglutaryl CoA reductase, HMGR), sucrose synthesis (sucrose phosphate synthase, SPS), and nitrogen assimilation (nitrate reductase, NR) (MacKintosh, 1992; Ball et al., 1994; Dale et al., 1995a; McMichael et al., 1995; Douglas et al., 1997; Sugden et al., 1999b; Nukarinen et al., 2016; Robertlee et al., 2017). Members of the class II T6P synthase (TPS) proteins are also phosphorylated by SnRK1, amongst other proteins (Glinski and Weckwerth, 2005; Harthill et al., 2006; Nukarinen et al., 2016). SnRK1 shares similar substrate recognition motifs with SNF1 and AMPK (Dale et al., 1995b), and is able to phosphorylate and inactivate mammalian HMGR and acetyl-CoA carboxylase (ACC) in the same sites as AMPK (MacKintosh, 1992). Importantly, SnRK1 orchestrates a broad transcriptional reprogramming to restore energy homeostasis through down-regulation of anabolism and up-regulation of catabolism (Baena-Gonzalez et al., 2007; Baena-Gonzalez and Sheen, 2008; Sheen, 2014). More precisely, SnRK1 induces genes related to nutrient remobilization via cell wall, starch, protein, and lipid degradation, as well as autophagy and gluconeogenesis, while repressing genes related to protein synthesis, the tricarboxylic acid (TCA) cycle, and glycolysis (Baena-Gonzalez et al., 2007; Baena-Gonzalez and Sheen, 2008). This is partly achieved through the direct phosphorylation and regulation of key transcription factors, such as bZIP63, by SnRK1 (Mair et al., 2015; Droge-Laser and Weiste, 2018). The transcriptional changes triggered by SnRK1 are remarkably similar to those induced by a variety of energy-limiting conditions (Baena-Gonzalez et al., 2007; Baena-Gonzalez and Sheen, 2008), reinforcing the role of SnRK1 as an energy sensor and central transcriptional regulator. Furthermore, this low-carbon transcriptional signature is conserved between woody and herbaceous species, highlighting its importance as a general mechanism to support essential maintenance functions and to reduce growth (Tarancon et al., 2017; Martin-Fontecha et al., 2018).

Under favorable energy conditions, TOR activation drives energy-consuming anabolic processes, such as protein synthesis and cell division, while repressing catabolism and nutrient remobilization, showing a clear reverse signature from the SNF1/AMPK/SnRK1 signaling outcome. Like SnRK1,TOR achieves this through phosphorylation of direct targets and through transcriptional reprogramming, affecting metabolic-, cell cycle-, signaling-, and transcription-related genes, amongst others. Phosphorylation and activation of E2F transcription factors by TOR promotes a transcriptional regulation of the heterotrophic to photoautotrophic transition and induction of root $(\mathrm{E} 2 \mathrm{Fa})$ and shoot $(\mathrm{E} 2 \mathrm{Fa} / \mathrm{b})$ meristem activity (Xiong et al., 2013; Li et al., 2017).

In addition, TOR is widely recognized for its positive regulation of translation, and this function appears to be conserved in plants (Schepetilnikov and Ryabova, 2018). Translational regulation exerted by mammalian TORC1 strongly depends on the direct phosphorylation of the S6 kinase (S6K) and its substrate, the S6 subunit of the ribosomal complex (RPS6), as well as on the phosphorylation of the translational repressors 4E-binding proteins (4EBPs), which dissociate from eIF4E allowing translation initiation (Fonseca et al., 2014). 
Some TORC1 direct targets, such as S6K and Tap42/ $\alpha 4$, and downstream effectors, such as RPS6, are also found in plant genomes, suggesting conserved functions (Mahfouz et al., 2006; Ahn et al., 2011; Dobrenel et al., 2016a; Schepetilnikov and Ryabova, 2018). Indeed, Tap46, a regulatory subunit of protein phosphatase $2 \mathrm{~A}$ in plants, has been associated with general translation and growth promotion, similar to its yeast and mammalian counterpart Tap42/a4 (Ahn et al., 2011; Ahn et al., 2015). Also, both S6K and RPS6 phosphorylation have been used as TOR signaling outputs in plants (Mahfouz et al., 2006; Schepetilnikov et al., 2011, 2013; Xiong and Sheen, 2012; Dobrenel et al., 2016b; Dong et al., 2017; Li et al., 2017; Wang et al., 2018). In addition to these targets, TOR stimulates translation via the phosphorylation of the translation initiation factor eIF3h, promoting translation reinitiation after upstream ORFs (Schepetilnikov et al., 2013). Additionally, TOR was shown to enter the nucleus and directly interact with the promoters of $r R N A$ genes to induce $r R N A$ expression required for ribosome biogenesis (Ren et al., 2011).

\section{Co-regulation}

In yeast and animals, SNF1 and AMPK are established upstream negative regulators of TOR. In animals, AMPK phosphorylates and activates the tuberous sclerosis complex 2 (TSC2) GTPaseactivating protein, which is a major inhibitor of the TORC1 pathway (Inoki et al., 2003), but that is absent in plants (van Dam et al.,2011). Moreover,AMPK phosphorylates RAPTOR, resulting in 14-3-3 binding and inhibition of TORC1 kinase activity (Gwinn et al., 2008). In yeast, SNF1 is required for repressing TORC1 in response to glucose starvation (Hughes Hallett et al., 2014), and specific inhibition of SNF1 with bulky ATP analogs results in reduced phosphorylation of TORC1 subunits (Braun et al., 2014). However, although inhibition of TORC1 appears to involve phosphorylation of the RAPTOR ortholog in yeast, KOG1, the site of phosphorylation, and its outcome differs from those in mammals (Hughes Hallett et al., 2015). In plants, control of TOR signaling by SnRK1 was also suggested to occur through phosphorylation of RAPTOR1B (Nukarinen et al., 2016). SnRK1 11 and RAPTOR1B transiently expressed in Nicotiana benthamiana were shown to colocalize and interact in the cytosol, and RAPTOR1B was phosphorylated by SnRK1 in in vitro kinase assays (Nukarinen et al., 2016). Although further mechanistic insight is required, it is tempting to speculate that this phosphorylation also occurs in vivo and that SnRK1 acts as an upstream negative regulator ofTOR in response to sugar deprivation, thereby feeding into the glucose-TOR axis in plants. Accordingly, in response to a night extension, plants with reduced SnRK1 activity had, compared with the wild type, higher phosphorylation levels of RPS6 and the eukaryotic translation initiation factor eIF5A (Nukarinen et al., 2016).

Furthermore, the extensive transcriptional reprogramming triggered by glucose-TOR signaling overlaps partially but significantly with SnRK1 target genes, showing an opposite regulation (e.g. regarding ribosomal protein genes) (Baena-Gonzalez et al., 2007; Xiong et al., 2013; Sheen, 2014). Conversely, partial TOR deficiency causes repression of genes involved in anabolism and biosynthetic pathways, and induces genes involved in catabolism, stress, and defense processes (Deprost et al., 2007; Moreau et al., 2012; Ren et al., 2012; Caldana et al., 2013), matching a SnRK1 signature. In the hypothalamus, leptin induces an inhibitory phosphorylation of AMPK $\alpha 2$ by the TOR direct target S6K, evidencing that TOR signaling may reciprocally regulate the AMPK pathway in animals (Dagon et al., 2012). However, this sort of co-regulation has not yet been described in plants.

Altogether, an increasing body of evidence supports that, as in other eukaryotes, part of the SnRK1 effects in plants are probably mediated by TOR signaling inhibition, in order to integrate the plant metabolic status with adequate growth and developmental decisions. Nevertheless, it is unlikely that all SnRK1 downstream effects are TOR dependent and that TOR regulation depends exclusively on SnRK1.

\section{SnRK1 and TOR: crosstalk under stress conditions}

Being sessile, plants have to cope with unfavorable environmental conditions as varied as drought, flooding, extreme temperatures, high salinity, or attacks from various pathogens (Mittler, 2006; Im et al., 2014). Most of these conditions restrict carbon assimilation through photosynthesis and/or ATP production through respiration, overall leading to a decrease in cellular energy levels (Biswal et al., 2011; Gururani et al., 2015). Additionally, resources that could be otherwise invested in growth have to be diverted into defense and stress tolerance, further compromising energy availability. Stress also causes profound alterations in source-sink interactions, as a consequence either of loss of specific parts (e.g. reproductive organs) or of actively prioritizing the growth of others (e.g. infected tissues or roots over shoots). This can reduce energy availability in certain organs whilst increasing it in others.

\section{Responses to biotic stress}

Biotic stress derives from the interaction between plants and diverse pathogenic organisms, including viruses, bacteria, fungi and oomycetes, nematodes, herbivores, and also competing plants. Plants evolved an innate immune system composed of surveillance mechanisms and effective responses to restrain pathogens, which aim to manipulate the host and cause disease (Boller and He, 2009; Dodds and Rathjen, 2010). The proposed 'zigzag' model of plant-pathogen interactions encompasses two branches of the plant immune system (Jones and Dangl, 2006). As a first line of defense, plants recognize extracellular conserved pathogen-associated or microbe-associated molecular patterns (PAMPs or MAMPs), such as fungal chitin, peptidoglycans, or bacterial flagellin, through pattern recognition receptors (PRR) localized on the cell surface. PRRs are generally composed of an extracellular leucine-rich repeat (LRR) domain and an intracellular kinase domain that upon recognition and activation launches pattern-triggered immunity (PTI). PTI includes a broad array of plant responses such as media alkalization, deposition of callose, reactive oxygen 
species (ROS) burst, phosphorylation of mitogen-activated protein kinases (MAPKs), synthesis of defense hormones, and activation of defense genes (Boller and $\mathrm{He}, 2009$; Dodds and Rathjen, 2010). In a second line of defense, plants respond to pathogen virulence factors, delivered into the host cell to counteract PTI and promote infection. Many of these pathogen effector proteins are recognized by intracellular nucleotide-binding (NB)-LRR receptors in the plant that boost a strong effector-triggered immunity (ETI) response. This can include activation of resistance (R)-genes and programmed cell death and autophagy as pro-survival mechanisms (Jones and Dangl, 2006; Dodds and Rathjen, 2010; Cui et al., 2015). Recently, signaling molecules such as sugars and hormones, protein kinases, and transcription factors were implicated in the switch between growth and defense upon pathogen perception (Wang et al., 2016; Filipe et al., 2018). The studies below unveil a prominent role in this switch also for SnRK1 and TOR, which contribute to balancing defense and growth in response to diverse biotic stresses.

\section{Plant-virus interactions}

Viruses manipulate plant defenses through multifunctional virulence factors in order to suppress antiviral gene silencing and hijack the transcriptional and translational machineries to sustain propagation.

Geminiviruses are a large family of ssDNA viruses that cause serious diseases in many crops. In tobacco, silencing $\operatorname{SnRK} 1 \alpha$ caused enhanced susceptibility to geminivirus infection, whereas overexpressing SnRK1 $\alpha$ led to increased resistance, albeit penalizing plant growth (Hao et al., 2003). Geminivirus pathogenicity determinants AL2 and L2 proteins cause enhanced susceptibility when expressed in transgenic tobacco plants (Sunter et al., 2001), presumably by directly inactivating SnRK1 (Hao et al., 2003) and adenosine kinase (ADK) (Wang et al., 2003). ADK targeting by viral effectors could be an indirect mechanism of SnRK1 down-regulation since ADK phosphorylates adenosine to generate 5'-AMP which in turn protects phosphorylated SnRK1 from inactivation by phosphatases (Sugden et al., 1999a). Furthermore, SnRK1 and ADK interact in vivo, possibly regulating each other (Mohannath et al., 2014). A repressive effect of AL2 on SnRK1 activity is further supported by overlapping transcriptional changes induced by AL2 overexpression and $S n R K 1 \alpha 2$ silencing (Liu et al., 2014). Geminivirus AL1 and AL2/C2 proteins also interact with the SnRK1 upstream kinases SnAKs/GRIKs, that accumulate in young tissues and infected leaves (Shen and Hanley-Bowdoin, 2006; Shen et al., 2009). On the other hand, SnRK1 has been shown to phosphorylate several viral proteins presumably to counteract viral infection. SnRK1 phosphorylates AL2/C2 proteins in vitro, and a virus expressing the corresponding AL2 phosphomimetic variant caused delayed symptom development and viral DNA accumulation during infection of Arabidopsis (Shen et al., 2014). More recently, SnRK1 was shown to phosphorylate a geminivirus Rep protein, impairing viral replication and thereby infection (Shen et al., 2018). The target residue is highly conserved, raising not only the possibility that SnRK1 phosphorylation of Rep is a common defense mechanism during infection, but also that this residue plays an important, as yet unknown role. In tomato plants, SnRK1 also interacts with and phosphorylates the geminivirus $\beta C 1$ protein, a pathogenicity determinant and suppressor of RNA silencing, thereby attenuating disease symptoms and reducing virus infection (Shen et al., 2011, 2012). SnRK1 was also found to interact with and phosphorylate REMORIN 4.1 (REM4.1), causing its proteasomal degradation. Given that AtREM4s enhance susceptibility to geminivirus infection and that they harbor motifs characteristic of proteins involved in cell division, the authors hypothesized that SnRK1 could block cell proliferation via REM4 inhibition (Son et al., 2014). Lastly, Tobacco mosaic virus (TMV) resistance protein N (TRPN) was retrieved as an SnRK1 interactor in an yeast two-hybrid screen from Glycine soja (Song et al., 2019).

The interaction of viral effectors with TOR in order to subvert host metabolism for viral benefit has also been described in several reports, but with an opposite outcome than when targeting SnRK1. Cauliflower mosaic virus (CaMV) TAV effector protein binds to TOR, promoting TOR activity and S6K1 phosphorylation in planta, which is critical for translation re-initiation and viral success. In agreement with this, TOR-deficient plants are resistant to CaMV infection (Schepetilnikov et al., 2011). As a result of TAV-TOR binding, plants infected with CaMV also became more susceptible to secondary bacterial infections, partly due to the suppression of salicylic acid (SA) production and autophagy (Zvereva et al., 2016). In a different study, TOR RNAi lines were partially resistant to the potyviruses Watermelon mosaic virus (WMV) and Turnip mosaic virus (TuMV) (Ouibrahim et al., 2015). Moreover, TOR inhibition by AZD-8055 hindered WMV systemic infection and was able to cure the plants. However, Col-0 plants treated with AZD-8055 were equally susceptible to TuMV infection, suggesting that potyviruses may differ in their requirement for TOR signaling (Ouibrahim et al., 2015).

\section{Plant-bacteria interactions}

Similarly to what has been described for plant-virus interactions, also in the case of bacterial infection, high SnRK1 activity has been generally linked to resistance, whereas high TOR activity has been generally linked to susceptibility.

Gene silencing experiments have shown that SnRK1 is required for cell death associated with the hypersensitive response (HR) elicited by the effector protein AvrBs1 from Xanthomonas campestris pv. vesicatoria $(X c v)$ to limit infection in resistant pepper plants. Pathogenicity of $X c v$ depends on the effector protein AvrBsT that acts to suppress the AvrBs1induced HR. AvrBsT interacts with SnRK1 in planta, suggesting that targeting SnRK1 might be important for HR suppression and for Xcv pathogenicity (Szczesny et al., 2010). Resistance of tomato to its pathogen Pseudomonas syringae pv tomato (Pst) has been correlated with the induction of cell death during infection, presumably through the inactivation of the plant cell death suppressor kinase AvrPto-dependent Pto-interacting protein3 (Adi3). Adi3, on the other hand, was shown to repress SnRK1 activity through phosphorylation of the SnRK1 $\beta$ subunit Gal83, supporting the idea that SnRK1 promotes the HR, and providing a potential mechanism for the cell death suppression outcome of Adi3 (Avila et al., 2012). 
SnRK1 has also been implicated in the resistance to Xanthomonas oryzae pv. oryzae (Xoo) in rice, with SnRK1A overexpression conferring enhanced resistance but causing a negative impact on plant growth and development (Filipe et al., 2018). However, it is unclear whether this resistance is general or dependent on the PRR host sensor XA21 (Seo et al., 2011; Filipe et al., 2018).

In a complementary study, the ectopic expression of TOR and RAPTOR in rice positively regulated growth and development as expected, but increased susceptibility to Xoo. In agreement with this, TOR inhibition with rapamycin activated many defense-related genes. The authors also showed that TOR suppresses PTI at least in part by counteracting signaling by the defense hormones SA and jasmonic acid (JA). Inhibiting TOR chemically or genetically, using RAPTOR 1 RNAi lines and the raptor1-1 mutant, resulted in decreased susceptibility to Xoo, highlighting that, as opposed to SnRK1, TOR is a negative regulator of disease resistance to Xoo in rice (De Vleesschauwer et al., 2018).

In Arabidopsis, TOR RNAi lines were more resistant to Pseudomonas syringae DC3000 (Pst), probably due to a faster and/or more effective defense response, whereas TOR overexpressors responded similarly to Col-0 to infection by $P_{s t}$ (Meteignier et al., 2017). However, TOR activity is not always induced by pathogens, as shown for Ralstonia solanacearum whose AWR5 effector inhibits TOR signaling (Popa et al., 2016). The reason behind this strategy is not clear but may be related to the increased nitrogen availability provided by autophagy and inhibition of protein synthesis.

\section{Plant-fungi and oomycete interactions}

SnRK1 and TOR have also been shown to be involved in defense responses against fungi and oomycetes, again in most cases associating high SnRK1 activity with enhanced resistance and high TOR activity with enhanced susceptibility.

In rice, $S n R K 1 A$ up-regulation and down-regulation led to resistance and susceptibility, respectively, against the rice blast pathogen Magnaporthe oryzae. Similar outcomes of resistance were also observed for the necrotrophic pathogens Cochliobolus miyabeanus and Rhizoctonia solani (Filipe et al., 2018). Furthermore, in response to inoculation with the blast fungus Pyricularia oryzae, SnRK1A overexpressors triggered a higher induction of SA- and JA-responsive genes associated with defense (Filipe et al., 2018). In a complementary study, overexpression of TOR and RAPTOR1 in rice rendered plants more susceptible to the necrotrophic fungi C. miyabeanus and R. solani. Likewise, TOR overexpressors and raptor1-1 mutants showed increased and decreased susceptibility, respectively, against the necrotrophic leaf fungus Botrytis cinerea and the soilborne vascular pathogen Verticillium longisporum. Inhibition of TOR activity with rapamycin had similar outcomes, strongly reducing infection by the biotrophic oomycete Bremia lactucae in lettuce seedlings (De Vleesschauwer et al., 2018). The authors also showed that TOR is a negative regulator of PTI. Pre-treatment of wild-type plants with chitin for $8 \mathrm{~h}$ triggered PTI, allowing a reduction of $30 \%$ in the diseased leaf area when plants were subsequently inoculated with C. miyabeanus. A similar reduction in disease severity was obtained in a
RAPTOR RNAi background but not in TOR-overexpressing plants, where the chitin-inducible resistance was almost completely suppressed (DeVleesschauwer et al., 2018).

Recently, down-regulation of TOR signaling in Arabidopsis, using either mutants impaired in TOR or wild-type plants treated with TOR inhibitors, was shown to increase resistance to Fusarium graminearum (Aznar et al., 2018), the causal agent of the Fusarium head blight disease in wheat. SnRK1 has also been indirectly implicated in the resistance to Fusarium (Perochon et al., 2015), through its interaction in planta with the wheat Fusarium Resistance Orphan Gene (FROG), a factor induced in response to the fungal virulence factor mycotoxin deoxynivalenol (DON) and that enhances resistance to DON and to F. graminearum.

The Arabidopsis SnRK1 $\beta \gamma$ subunit interacts with HSPRO1/2 proteins involved in plant defense and possibly in the leaf senescence program (Gissot et al., 2006). Infection of Nicotiana attenuata seedlings with the fungus Piriformospora indica promotes seedling growth through a process negatively regulated by plant HSPRO and by SnRK1 $\beta$ subunit Gal83. Since $N$. attenuata seedlings silenced in Gal83 and HSPRO, either independently or simultaneously, display enhanced growth to a similar extent upon infection, it is likely that HSPRO acts via SnRK1 in the seedling growth promoted by $P$. indica (Schuck et al., 2012, 2013).

Additional potential connections to plant immunity come from the interaction of SnRK1 catalytic subunits with STKR1, a protein whose overexpression affects genes related to systemic acquired resistance (SAR) and confers resistance towards the biotrophic oomycete Hyaloperonospora arabidopsidis (Hpa) (Nietzsche et al., 2016, 2018). In a different study, TOR silencing through RNAi increased resistance to Hpa in Arabidopsis, whereas overexpression of TOR rendered plants significantly more susceptible to this pathogen (Meteignier et al., 2017).

\section{Other plant biotic interactions}

In response to herbivory, $N$. attenuata plants increase the allocation of sugars to roots (Schwachtje et al., 2006). This strategy of carbon diversion to a less vulnerable location within the plant is regulated by the SnRK1 $\beta$ subunit Gal83, namely through Gal83 transcriptional down-regulation in source leaves upon herbivore attack, and seems to be independent of JA signaling. Plants with enhanced root reserves have prolonged reproduction and have delayed senescence (Schwachtje et al., 2006).

Interestingly, microbes synthesize signaling molecules such as sugars and hormones that may interfere with the SnRK1TOR axis in the host, inhibiting SnRK1 and/or promoting TOR signaling, and thereby modulating growth and defense to promote infection. Pathogens such as Pseudomonas syringae and Agrobacterium tumefaciens can directly synthesize auxin or manipulate auxin synthesis and signaling in plants to suppress plant defense (Huot et al., 2014). Auxin promotes growthrelated processes that aid pathogen proliferation and indirectly interfere with SA-mediated defense (Naseem and Dandekar, 2012). As previously mentioned, auxin activates TOR signaling in plants (Schepetilnikov et al., 2013, 2017; Li et al., 2017), and TOR reciprocally impacts auxin signaling (Dong et al., 2015; Deng et al., 2016). Likewise, bacteria and fungi produce 
trehalose, and its biosynthesis and metabolism play important roles in their pathogenicity (Fernandez et al., 2010; Hulsmans et al., 2016), possibly involving the inhibition of SnRK1 by the trehalose precursor T6P (Zhang et al., 2009; Nunes et al., 2013b; Lunn et al., 2014). Notwithstanding, trehalose is also considered a plant stress protector that elicits plant defense mechanisms (Fernandez et al., 2010).

Recently, a role in growth regulation was also shown for other defense-related metabolites, glucosinolates (Malinovsky et al., 2017). This study demonstrated that the aliphatic glucosinolate 3-hydroxypropylglucosinolate arrests root growth and development via TOR signaling inhibition, unveiling a role for this metabolite in the coordination of plant defense and growth.

\section{Responses to abiotic stress}

SnRK1 signaling is now widely accepted to be activated under conditions that compromise energy production, such as unexpected darkness and extended night treatments, herbicide feeding, or hypoxia (Baena-Gonzalez et al., 2007; Cho et al., 2012; Rodrigues et al., 2013; Mair et al., 2015; Cho et al., 2016; Nukarinen et al., 2016; Weiste et al., 2017). This has been shown using the induction of SnRK1 marker genes or target phosphorylation as readout of SnRK1 activity (Baena-Gonzalez et al., 2007; Cho et al., 2012; Mair et al., 2015; Cho et al., 2016; Nukarinen et al., 2016). Using in vitro kinase activity assays for the synthetic peptides SAMS, AMARA, or SPS, SnRK1 kinase activity was also shown to increase in response to low nutrients in Arabidopsis seedlings (Ananieva et al., 2008), bean seeds (Coello and Martinez-Barajas, 2014a, 2016), and maize kernels (Bledsoe et al., 2017). Accordingly, it increased in response to non-metabolizable glucose analogs such as 2-deoxyglucose (Harthill et al., 2006), and decreased in the presence of glucose (Ananieva et al., 2008) in Arabidopsis. However, at high concentrations, glucose was reported to induce SnRK1 activity, probably as a result of the glucose-induced increase in abscisic acid (ABA) levels (Jossier et al., 2009), that in turn activate SnRK1 signaling (Rodrigues et al., 2013). In addition, Arabidopsis SnRK1 activity was reported to increase under nitrogen deficiency (Nunes et al., 2013a) and decrease under phosphate starvation (Fragoso et al., 2009).

Unlike SnRK1, TOR activity is usually down-regulated under stress conditions that restrict sugar availability. For example, in root meristems of Arabidopsis seedlings, growing in sugar-free liquid medium, TOR activity assessed by S6K phosphorylation at T-449 is inhibited upon starvation and darkness, but can be restored by exogenous glucose supply (Xiong et al., 2013; Li et al., 2017). In the shoot meristem of plants grown under the same conditions, TOR activity is equally inhibited, but, to restore it, both glucose and light are required ( $\mathrm{Li}$ et al., 2017). A decrease in S6K phosphorylation or activity was also reported to occur in Arabidopsis in response to osmotic stress (Mahfouz et al., 2006), cold stress (Wang et al., 2017), and sulfate depletion (Dong et al., 2017). Interestingly the effect of sulfate was not direct but was transduced into the TOR pathway through down-regulation of glucose metabolism. Accordingly, glucose feeding ameliorated Arabidopsis sulfur deficiency phenotypes (Dong et al., 2017) and it was proposed that this regulation of TOR could be mediated through SnRK1. Curiously, the ability of rapamycin to inhibit TOR via AtFKBP12 binding was shown to be enhanced under hypoxic conditions (Deng et al., 2016).

In line with the regulation of SnRK1 and TOR by multiple stress conditions, plants with manipulated SnRK1 or TOR activities display altered abiotic stress resistance. Overall, higher SnRK1 levels lead to higher stress resistance, while lower SnRK1 levels result in higher stress sensitivity; however, growth or developmental effects are often observed in both cases. For example, overexpression of SnRK1 $\alpha 1$ in Arabidopsis enhanced seedling resistance to starvation, but delayed development (Baena-Gonzalez et al., 2007). Similar observations were reported recently, also in Arabidopsis, with SnRK1 $\alpha 1$ overexpressors displaying higher resistance not only to carbon, but also to nitrogen starvation (Chen et al., 2017). Under heat stress, SnRK1 phosphorylation of FUSCA3 (Tsai and Gazzarrini, 2012) is important for seed formation, as fus 3 mutants complemented with a FUSCA3 version mutated in the SnRK1targeted phosphorylation site displayed higher abortion rates and poor progeny growth (Chan et al., 2017). Arabidopsis seedlings overexpressing rice or Arabidopsis SnRK1 $\alpha 1$ also showed higher resistance to submergence, in part through direct SnRK1 1 1 binding to chromatin to regulate gene expression (Cho et al., 2012). An independent study confirmed these results, reporting higher recovery rates after submergence and also after drought (Chen et al., 2017). Consistent with this, plants with reduced SnRK1 activity caused by overexpression of a kinase-dead SnRK1 11 variant were more susceptible to submergence (Cho et al., 2016). In potato, silencing of the $\beta$ subunit Gal83 increased salt sensitivity and yielded plants with stunted roots with smaller cells, and a larger number of tubers, albeit of reduced size (Lovas et al., 2003). When SnRK1 was silenced in pea seeds through a similar approach, gene expression also indicated higher stress susceptibility, and, again, SnRK1-silenced seeds had lower fresh weight than the wild type (Radchuk et al., 2006). In Arabidopsis, transient silencing of $\operatorname{SnRK1}$ through virus-induced gene silencing generated dwarf plants unable to induce starvation genes upon hypoxia, dark, or herbicide treatments (Baena-Gonzalez et al., 2007).

In agreement with the increased stress tolerance of SnRK1 $\alpha 1$ overexpressors, raptor $B$ mutants, with reduced TOR activity, scored higher survival and recovery after a prolonged darkness treatment, although the authors attributed this to the higher starch accumulation of the mutants (Salem et al., 2018). Also, transgenic plants overexpressing the TOR target S6K showed increased sensitivity to osmotic stress (Mahfouz et al., 2006).

Curiously, and unlike what generally happens in biotic stress responses, numerous studies report enhanced abiotic stress resistance for plants with high TOR activities. Plants overexpressing TOR were more resistant to osmotic stress and developed longer roots, whereas TOR silencing had the opposite effect (Deprost et al., 2007). In the TOR-impaired lst 8 mutant, the synthesis of osmoprotectants was decreased, which could be one of the reasons why TOR RNAi lines were more sensitive (Moreau et al., 2012). In agreement with this, germination assays of raptor $1 b$ mutants under osmotic or salt stress also 
revealed higher sensitivity (Salem et al., 2017) and TOR RNAi lines displayed higher sensitivity to nitrogen starvation (Liu and Bassham, 2010). Recently, transgenic rice plants overexpressing TOR also displayed higher growth, yield potential, and life span under water deficit (Bakshi et al., 2017). Chlorophyll degradation in these TOR overexpressors was slower than in the wild type, and expression of specific stress genes was highly up-regulated (Bakshi et al., 2017). Likewise, TOR activity is required for cold stress responses, as TOR RNAi lines were more sensitive to cold stress (Dong et al., 2019). In line with these observations is the recent report of higher grain yield and higher drought resistance of spring wheat plants treated with synthetic and light-activated T6P precursors (Griffiths et al., 2016; Paul et al., 2018). Presumably one of the mechanisms through which these precursors conferred drought tolerance was SnRK1 inhibition, which could subsequently activate TOR (Griffiths et al., 2016).

One of the best studied mechanisms through which SnRK1 and TOR contribute to stress responses is autophagy, an evolutionarily conserved process in which eukaryotic cells degrade damaged or unnecessary cellular components, generating new building blocks and energy sources that are essential during stress (Ustun et al., 2017; Avin-Wittenberg, 2018).

Similarly to the situation in yeast and mammals, SnRK1 and TOR have been shown to affect autophagy in plants in a positive and negative manner, respectively (Alers et al., 2012; $\mathrm{Pu}$ et al., 2017b; Soto-Burgos et al., 2018). Under normal growth conditions, overexpression of the SnRK1a1 catalytic subunit was sufficient to induce constitutive autophagy (Chen et al., 2017; Soto-Burgos and Bassham, 2017), and decreasing TOR activity chemically or genetically had similar effects (Liu and Bassham, 2010; Pu et al., 2017a; Salem et al., 2018). Importantly, when both SnRK1 and TOR activities were simultaneously increased, constitutive autophagy was not induced or was induced to a lower extent, whereas decreasing both SnRK1 and TOR activities resulted in constitutive autophagy; this suggests that SnRK1 is upstream of TOR in autophagy regulation (Soto-Burgos and Bassham, 2017). Activation of autophagy under salt, osmotic, starvation, oxidative, and endoplasmic reticulum (ER) stress requires SnRK1, as snrk1a1 mutants were impaired in autophagy under these conditions (Soto-Burgos and Bassham, 2017). Interestingly, increasing TOR activity by overexpressing TOR or by auxin treatment decreased autophagy levels in response to all conditions except oxidative and ER stress $(\mathrm{Pu}$ et al., 2017a), suggesting that SnRK1 can activate autophagy in both a TOR-dependent and -independent manner (SotoBurgos and Bassham, 2017). In addition, genetic analyses show that the higher tolerance of SnRK1 $1 \alpha 1$ overexpressors to drought, carbon and nitrogen starvation, and submergence is autophagy dependent (Chen et al., 2017). Interestingly, autophagy seems to be important also for degrading positive growth regulators. The brassinosteroid signaling transcription factor BZR1 is stabilized by TOR in the presence of sugars, and is degraded under low carbon conditions in an autophagy-dependent manner, thereby allowing the integration of carbon availability with growth-promoting hormonal programs (Zhang et al., 2016).
ABA signaling is another important pathway through which SnRK1 and TOR can affect stress responses. Links between SnRK1 and ABA signaling have been established in numerous studies. Arabidopsis SnRK1 $\alpha 1$ overexpressors are ABA hypersensitive (Jossier et al., 2009), and SnRK1 has been proposed to mediate ABA effects during seed maturation and filling in pea, possibly through ABI3 (Radchuk et al., 2006, 2010). Also, SnRK1 purified from spinach leaves or immunoprecipitated from Arabidopsis seedling extracts was able to phosphorylate in vitro $\mathrm{ABI} 5$ and $\mathrm{AREBP}$ transcription factor peptides containing two conserved SnRK1 phosphorylation motifs (Zhang et al., 2008; Bitrian et al., 2011). Importantly, ABA can activate SnRK1 signaling through the action of PP2Cs that act as negative regulators of SnRK1. Consequently, SnRK1 and ABA induce largely overlapping transcriptional responses (Rodrigues et al., 2013). In contrast, TOR overexpressors in rice display $A B A$ insensitivity during germination (Bakshi et al., 2017), whereas Arabidopsis raptor1b mutants are hypersensitive (Salem et al., 2017). Very recently, a balance between growth and stress responses was reported to be established through the reciprocal regulation between TOR and ABA stress signaling. Under favorable conditions, TOR phosphorylates the PYL ABA receptors, precluding their association with $\mathrm{ABA}$ and PP2C phosphatases, and leading to the inactivation of SnRK2 kinases and of stress responses. Conversely, when ABA signaling is induced under stress conditions, TOR is inactivated in an SnRK2 kinase-dependent manner to repress growth (Rosenberger and Chen, 2018; Wang et al., 2018).

\section{Concluding remarks}

The concept of growth-defense trade-offs is widely accepted and very intuitive; under stress, besides having to cope with limited resources, plants need to divert available energy from growth to defense in order to survive. For plants, this tradeoff is important for survival, but for agriculture it is the cause of vast yield losses. Given the relevance of SnRK1 and TOR for balancing stress responses with growth and development, their signaling pathways could be valuable targets of manipulations aimed to increase plant performance and productivity in suboptimal environments. However, although it is increasingly clear that the SnRK1-TOR interplay contributes, at least partly, to balancing growth and defense, numerous studies also show that the influence of SnRK1 and TOR in defense and growth outputs is not always straightforward (Supplementary Table S1).

Under biotic stress, the clear growth-defense trade-offs that are often observed fit well with a model in which SnRK1 and TOR play antagonistic roles. Under pathogen attack, SnRK1 promotes broad disease resistance and plant fitness at the expense of growth, whilst TOR promotes growth and proliferation, compromising immunity and rendering plants more susceptible to a broad range of pathogens. Accordingly, SnRK1 gain- and TOR loss-of-function plants tend to be more resistant, whereas TOR gain- and SnRK1 loss-of-function plants tend to be more susceptible. Several pathogens target these specific pathways in the host, modulating them to inhibit SnRK1 
and/or activate TOR signaling to promote infection. However, a recent study suggested that pathogens can also repress TOR signaling, implying that under certain conditions, specific pathogens, or stages of infection, TOR signaling inhibition could also benefit infection.

The situation becomes less intuitive when considering abiotic stress. Despite a few exceptions, most reports show that both SnRK1 and TOR overexpressors are more resistant than wild-type plants to abiotic stress, whereas loss-of-function mutants for both SnRK1 and TOR are more susceptible. These seemingly conflicting results, in which both SnRK1 and TOR seem to promote tolerance to abiotic stress, are harder to reconcile with their antagonist roles, but can perhaps be explained by the specific nature, intensity, and duration of the treatments applied in each study and by the strategies deployed by plants to cope with each particular treatment. Compromised TOR activity was reported to be detrimental under situations of osmotic stress (Deprost et al., 2007) and prolonged cold treatment (Dong et al., 2019), where perhaps the role of TOR in the biosynthesis of osmoprotective sugars and amino acids may be critical for survival. On the other hand, rice TOR overexpressors performed better and returned higher yields than wildtype plants after prolonged growth in limited water conditions (Bakshi et al., 2017). Although not measured in this study, such gradual drought stress is likely to alter shoot:root ratios, promoting active growth of the root system at the expense of the shoot. Under such conditions, the presumably enhanced capacity of the TOR overexpressors to develop a larger root should increase water absorption and lead to improved performance.

Altogether, while in biotic stress, growth is often associated with pathogen replication and propagation, in abiotic stress, investing resources in growth is often one of the ways to adapt. This happens, for example, under drought and several nutrient limitations, where increased root growth and altered root architecture constitute important survival strategies.

This interpretation is in line with the emerging relationship and functions of SnRK1 and TOR (Fig. 1). TOR primarily regulates growth while SnRK1 primarily regulates energy homeostasis, thereby promoting stress tolerance and defense. TOR growth-promoting effects may compromise or, in striking contrast, improve the strategies deployed by plants to cope with particular environments. On the other hand, SnRK1 senses environmental information in the form of the "energy status', modulating growth according to the conditions (BaenaGonzalez et al., 2007; Jossier et al., 2009; Cho et al., 2012). In Arabidopsis, SnRK1a1 overexpressors and SnRK1 transient loss-of-function seedlings grew, respectively, more and less than the wild type in nutrient-deprived conditions but, upon exogenous sugar supply, the growth effects were completely reversed (Baena-Gonzalez et al., 2007). Furthermore, SnRK1 1 1 overexpressors subjected to high trehalose concentrations that induce developmental arrest in the wild type were still able to develop

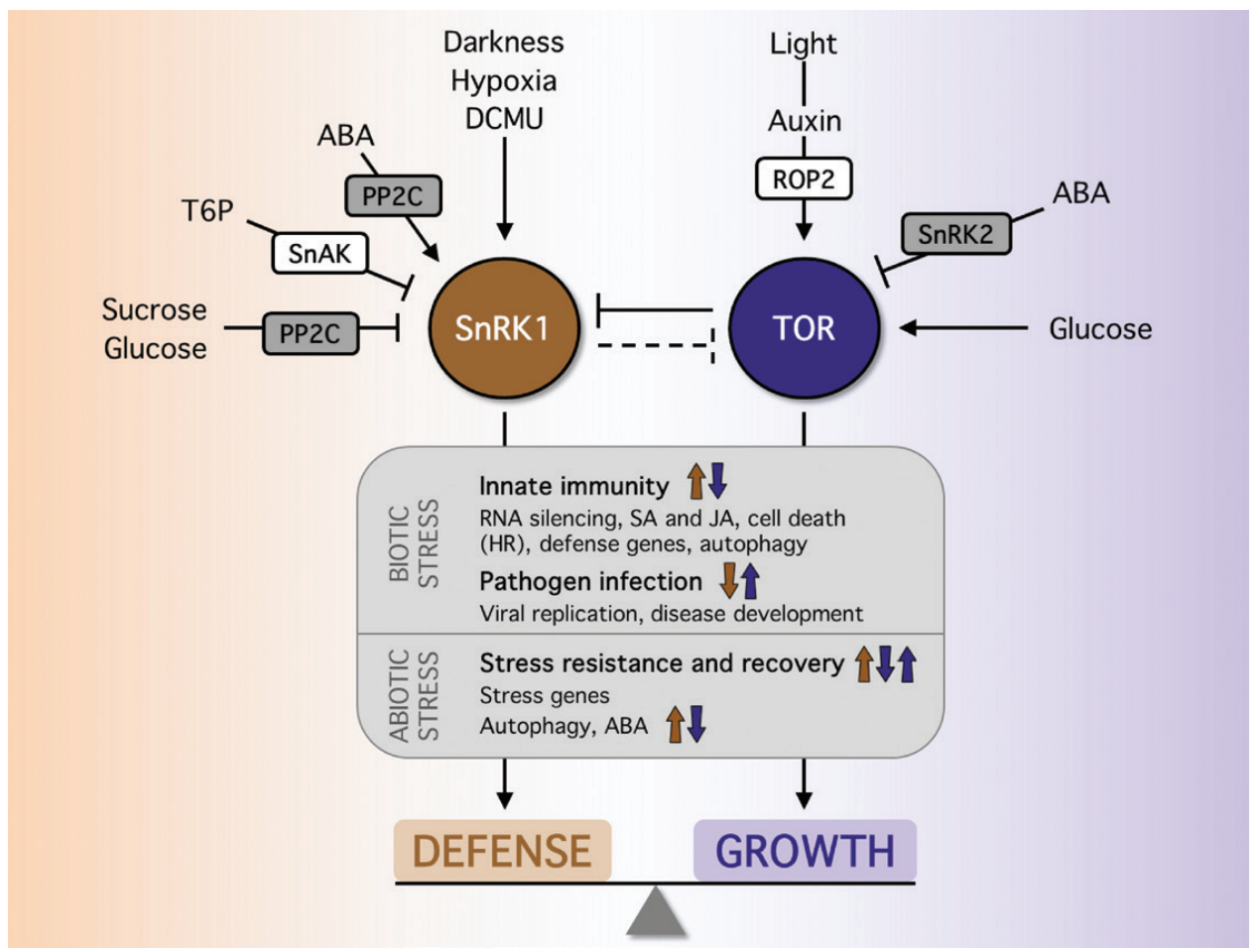

Fig. 1. SnRK1 and TOR are central metabolic regulators that play largely antagonistic roles in growth and defense in plants. Under unfavorable conditions when energy production is compromised by biotic or abiotic stress factors, SnRK1 is activated to induce stress responses and defense, whilst TOR is repressed. Conversely, under optimal conditions when sufficient light, water, and nutrients are available, SnRK1 is repressed whilst TOR is activated to drive processes associated with cell proliferation and growth. Growth-defense trade-offs may result from a negative cross-regulation between SnRK1 and TOR, as well as through their independent regulation of downstream processes. Components highlighted in gray and white designate negative and positive regulators, respectively, of the indicated kinase. Color-coded upward and downward arrows designate positive and negative effects, respectively, of the corresponding kinase in downstream processes. SnRK1 (Snf1-related protein kinase 1), TOR (target of rapamycin), PP2Cs (type 2C protein phosphatases), SnAK (SnRK1 activating kinase), ROP2 (small GTPase Rho-related protein 2), SnRK2 (Snf1-related protein kinase 2). 
roots and grow (Delatte et al., 2011). However, whether in these and other cases the growth outcomes of SnRK1-manipulated plants can be explained by changes in TOR activity, or the defense outcomes of TOR-manipulated plants can be explained by changes in SnRK1 activity is presently unknown.

Testing plants with manipulated levels of both complexes in similar conditions would provide useful insight on their mutual relationship. So far this has only been carried out for autophagy, in which it seems clear that SnRK1 is upstream of TOR, promoting autophagy in both a TOR-dependent and -independent manner. Interestingly, a recent study showed that serat mutants, impaired in the conversion of serine to O-acetylserine, exhibited defective growth under normal conditions despite having normal TOR activity outputs (Dong et al., 2017). This shows that TOR activity and growth are not always necessarily coupled.

The scenario becomes increasingly complex when considering the possibility that SnRK1 and TOR may be regulated differently in source and sink organs, as reports indicate variability in SnRK1 activity or response to sugars, possibly by associating with different interactors (Zhang et al., 2009; Piattoni et al., 2011; Coello and Martinez-Barajas, 2014b). Also the opposite effects reported for sugars on SnRK1 (sometimes inhibitory and sometimes inductive) might be explained by the use of heterotrophic versus autotrophic tissues in different studies (Baena-Gonzalez and Sheen, 2008; Halford and Hey, 2009). Furthermore, TOR is mostly expressed in actively dividing tissues (Menand et al., 2002) and, therefore, the detrimental effects of lacking TOR activity might be particularly relevant in young seedlings and in conditions where meristematic activity is required.

In summary, SnRK1 and TOR play important regulatory roles in fundamental growth and defense processes, but the outcome of their action is largely dependent on the conditions the plant encounters. Knowledge of the molecular mechanisms governing SnRK1 and TOR signaling is rapidly increasing as well as evidence for their cross-regulation. Since both growth and defense are required in the field to ensure maximum crop yield, an optimal fine-tuning of the SnRK1-TOR rheostat in accordance with the prevailing conditions could lead to agriculture production meeting its full potential.

\section{Supplementary data}

Supplementary data are available at $J X B$ online.

Table S1. Biotic and abiotic stress-related phenotypes associated with altered SnRK1 and TOR signaling.

\section{Acknowledgements}

We apologize to the many authors whose work was not cited due to space limitations. This work was supported by the Fundação para a Ciência e a Tecnologia projects UID/Multi/04551/2013, PTDC/ BIA-PLA/7143/2014, LISBOA-01-0145-FEDER-028128, and PTDC/BIA-BID/32347/2017, and by fellowships/contracts SFRH/
BPD/116116/2016 (LM), SFRH/BPD/109336/2015 (AC), and IF/00804/2013 (EBG).

\section{References}

Ahn CS, Ahn HK, Pai HS. 2015. Overexpression of the PP2A regulatory subunit Tap46 leads to enhanced plant growth through stimulation of the TOR signalling pathway. Journal of Experimental Botany 66, 827-840.

Ahn CS, Han JA, Lee HS, Lee S, Pai HS. 2011. The PP2A regulatory subunit Tap46, a component of the TOR signaling pathway, modulates growth and metabolism in plants. The Plant Cell 23, 185-209.

Alers S, Löffler AS, Wesselborg S, Stork B. 2012. Role of AMPKmTOR-Ulk $1 / 2$ in the regulation of autophagy: cross talk, shortcuts, and feedbacks. Molecular and Cellular Biology 32, 2-11.

Ananieva EA, Gillaspy GE, Ely A, Burnette RN, Erickson FL. 2008 Interaction of the WD40 domain of a myoinositol polyphosphate 5-phosphatase with SnRK1 links inositol, sugar, and stress signaling. Plant Physiology 148, 1868-1882.

Anderson GH, Veit B, Hanson MR. 2005. The Arabidopsis AtRaptor genes are essential for post-embryonic plant growth. BMC Biology $\mathbf{3}, 12$.

Avila J, Gregory OG, Su D, Deeter TA, Chen S, Silva-Sanchez C, Xu S, Martin GB, Devarenne TP. 2012. The $\beta$-subunit of the SnRK1 complex is phosphorylated by the plant cell death suppressor Adi3. Plant Physiology 159, 1277-1290.

Avin-Wittenberg T. 2018. Autophagy and its role in plant abiotic stress management. Plant, Cell \& Environment. doi: 10.1111/pce.13404.

Aznar NR, Consolo VF, Salerno GL, Martínez-Noël GMA. 2018. TOR signaling downregulation increases resistance to the cereal killer Fusarium graminearum. Plant Signaling \& Behavior 13, e1414120.

Baena-González E, Hanson J. 2017. Shaping plant development through the SnRK1-TOR metabolic regulators. Current Opinion in Plant Biology 35, 152-157.

Baena-González E, Rolland F, Thevelein JM, Sheen J. 2007. A central integrator of transcription networks in plant stress and energy signalling. Nature 448, 938-942.

Baena-González E, Sheen J. 2008. Convergent energy and stress signaling. Trends in Plant Science 13, 474-482.

Bakshi A, Moin M, Kumar MU, Reddy AB, Ren M, Datla R, Siddiq EA, Kirti PB. 2017. Ectopic expression of Arabidopsis target of rapamycin (AtTOR) improves water-use efficiency and yield potential in rice. Scientific Reports 7, 42835.

Ball KL, Dale S, Weekes J, Hardie DG. 1994. Biochemical characterization of two forms of 3-hydroxy-3-methylglutaryl-CoA reductase kinase from cauliflower (Brassica oleracia). European Journal of Biochemistry 219, 743-750.

Bendayan M, Londono I, Kemp BE, Hardie GD, Ruderman N, Prentki M. 2009. Association of AMP-activated protein kinase subunits with glycogen particles as revealed in situ by immunoelectron microscopy. Journal of Histochemistry and Cytochemistry 57, 963-971.

Biswal B, Joshi PN, Raval MK, Biswal UC. 2011. Photosynthesis, a global sensor of environmental stress in green plants: stress signalling and adaptation. Current Science 101, 47-56.

Bitrián M, Roodbarkelari F, Horváth M, Koncz C. 2011. BACrecombineering for studying plant gene regulation: developmental control and cellular localization of SnRK1 kinase subunits. The Plant Journal 65, 829-842.

Bledsoe SW, Henry C, Griffiths CA, Paul MJ, Feil R, Lunn JE, Stitt M, Lagrimini LM. 2017. The role of Tre6P and SnRK1 in maize early kerne development and events leading to stress-induced kernel abortion. BMC Plant Biology 17, 74.

Boller T, He SY. 2009. Innate immunity in plants: an arms race between pattern recognition receptors in plants and effectors in microbial pathogens. Science 324, 742-744.

Braun KA, Vaga S, Dombek KM, Fang F, Palmisano S, Aebersold R, Young ET. 2014. Phosphoproteomic analysis identifies proteins involved in transcription-coupled mRNA decay as targets of Snf1 signaling. Science Signaling 7, ra64. 
Bray E, Bailey-Serres J, Weretilnyk E. 2000. Responses to abiotic stresses. In: Buchanan BB, Gruissem W, Jones RL, eds. Biochemistry \& molecular biology of plants. Rockville, MD: ASPB, 1158-1203.

Broeckx T, Hulsmans S, Rolland F. 2016. The plant energy sensor: evolutionary conservation and divergence of SnRK1 structure, regulation, and function. Journal of Experimental Botany 67, 6215-6252.

Caldana C, Li Y, Leisse A, Zhang Y, Bartholomaeus L, Fernie AR, Willmitzer L, Giavalisco P. 2013. Systemic analysis of inducible target of rapamycin mutants reveal a general metabolic switch controlling growth in Arabidopsis thaliana. The Plant Journal 73, 897-909.

Chan A, Carianopol C, Tsai AY, Varatharajah K, Chiu RS, Gazzarrini S. 2017. SnRK1 phosphorylation of FUSCA3 positively regulates embryogenesis, seed yield, and plant growth at high temperature in Arabidopsis. Journal of Experimental Botany 68, 4219-4231.

Chen L, Su ZZ, Huang L, Xia FN, Qi H, Xie LJ, Xiao S, Chen QF. 2017. The AMP-activated protein kinase KIN10 is involved in the regulation of autophagy in Arabidopsis. Frontiers in Plant Science 8, 1201.

Cho HY, Wen TN, Wang YT, Shih MC. 2016. Quantitative phosphoproteomics of protein kinase SnRK1 regulated protein phosphorylation in Arabidopsis under submergence. Journal of Experimental Botany 67, 2745-2760.

Cho YH, Hong JW, Kim EC, Yoo SD. 2012. Regulatory functions of SnRK1 in stress-responsive gene expression and in plant growth and development. Plant Physiology 158, 1955-1964.

Coello P, Hirano E, Hey SJ, Muttucumaru N, Martinez-Barajas E, Parry MA, Halford NG. 2012. Evidence that abscisic acid promotes degradation of SNF1-related protein kinase (SnRK) 1 in wheat and activation of a putative calcium-dependent SnRK2. Journal of Experimental Botany 63, 913-924.

Coello P, Martínez-Barajas E. 2014a. The activity of SnRK1 is increased in Phaseolus vulgaris seeds in response to a reduced nutrient supply. Frontiers in Plant Science 5, 196.

Coello P, Martínez-Barajas E. 2014b. SnRK1 is differentially regulated in the cotyledon and embryo axe of bean (Phaseolus vulgaris L) seeds. Plant Physiology and Biochemistry 80, 153-159.

Coello P, Martínez-Barajas E. 2016. Changes in nutrient distribution are part of the mechanism that promotes seed development under severe nutrient restriction. Plant Physiology and Biochemistry 99, 21-26.

Crozet P, Jammes F, Valot B, Ambard-Bretteville F, Nessler S, Hodges M, Vidal J, Thomas M. 2010. Cross-phosphorylation between Arabidopsis thaliana sucrose nonfermenting 1-related protein kinase 1 (AtSnRK1) and its activating kinase (AtSnAK) determines their catalytic activities. Journal of Biological Chemistry 285, 12071-12077.

Crozet P, Margalha L, Confraria A, Rodrigues A, Martinho C, Adamo M, Elias CA, Baena-González E. 2014. Mechanisms of regulation of SNF1/AMPK/SnRK1 protein kinases. Frontiers in Plant Science 5, 190.

Cui H, Tsuda K, Parker JE. 2015. Effector-triggered immunity: from pathogen perception to robust defense. Annual Review of Plant Biology 66, 487-511.

Dagon Y, Hur E, Zheng B, Wellenstein K, Cantley LC, Kahn BB. 2012. p70S6 kinase phosphorylates AMPK on serine 491 to mediate leptin's effect on food intake. Cell Metabolism 16, 104-112.

Dale S, Arró M, Becerra B, Morrice NG, Boronat A, Hardie DG, Ferrer A. 1995a. Bacterial expression of the catalytic domain of 3-hydroxy3-methylglutaryl-CoA reductase (isoform HMGR1) from Arabidopsis thaliana, and its inactivation by phosphorylation at Ser577 by Brassica oleracea 3-hydroxy-3-methylglutaryl-CoA reductase kinase. European Journal of Biochemistry 233, 506-513.

Dale S, Wilson WA, Edelman AM, Hardie DG. 1995b. Similar substrate recognition motifs for mammalian AMP-activated protein kinase, higher plant HMG-CoA reductase kinase-A, yeast SNF1, and mammalian calmodulin-dependent protein kinase I. FEBS Letters 361, 191-195.

Delatte TL, Sedijani P, Kondou Y, Matsui M, de Jong GJ, Somsen GW, Wiese-Klinkenberg A, Primavesi LF, Paul MJ, Schluepmann H. 2011. Growth arrest by trehalose-6-phosphate: an astonishing case of primary metabolite control over growth by way of the SnRK1 signaling pathway. Plant Physiology 157, 160-174.

Deng K, Yu L, Zheng X, Zhang K, Wang W, Dong P, Zhang J, Ren M. 2016. Target of rapamycin is a key player for auxin signaling transduction in Arabidopsis. Frontiers in Plant Science 7, 291.
Deprost D, Truong HN, Robaglia C, Meyer C. 2005. An Arabidopsis homolog of RAPTOR/KOG1 is essential for early embryo development. Biochemical and Biophysical Research Communications 326, 844-850.

Deprost D, Yao L, Sormani R, Moreau M, Leterreux G, Nicolaï M, Bedu M, Robaglia C, Meyer C. 2007. The Arabidopsis TOR kinase links plant growth, yield, stress resistance and mRNA translation. EMBO Reports 8, 864-870.

De Vleesschauwer D, Filipe O, Hoffman G, et al. 2018. Target of rapamycin signaling orchestrates growth-defense trade-offs in plants. New Phytologist 217, 305-319.

Dobrenel T, Caldana C, Hanson J, Robaglia C, Vincentz M, Veit B, Meyer C. 2016a. TOR signaling and nutrient sensing. Annual Review of Plant Biology 67, 261-285.

Dobrenel T, Mancera-Martínez E, Forzani C, et al. 2016b. The Arabidopsis TOR kinase specifically regulates the expression of nuclear genes coding for plastidic ribosomal proteins and the phosphorylation of the cytosolic ribosomal protein S6. Frontiers in Plant Science 7, 1611.

Dodds PN, Rathjen JP. 2010. Plant immunity: towards an integrated view of plant-pathogen interactions. Nature Reviews Genetics 11, 539-548.

Dong P, Xiong F, Que Y, Wang K, Yu L, Li Z, Ren M. 2015. Expression profiling and functional analysis reveals that TOR is a key player in regulating photosynthesis and phytohormone signaling pathways in Arabidopsis. Frontiers in Plant Science 6, 677.

Dong Y, Silbermann M, Speiser A, et al. 2017. Sulfur availability regulates plant growth via glucose-TOR signaling. Nature Communications $\mathbf{8}$, 1174.

Dong Y, Teleman AA, Jedmowski C, Wirtz M, Hell R. 2019. The Arabidopsis THADA homologue modulates TOR activity and cold acclimation. Plant Biology 21 Suppl 1, 77-83.

Douglas P, Pigaglio E, Ferrer A, Halfords NG, MacKintosh C. 1997. Three spinach leaf nitrate reductase-3-hydroxy-3-methylglutaryl-CoA reductase kinases that are regulated by reversible phosphorylation and/or $\mathrm{Ca}^{2+}$ ions. Biochemical Journal 325, 101-109.

Dröge-Laser W, Weiste C. 2018. The C/S1 bZIP network: a regulatory hub orchestrating plant energy homeostasis. Trends in Plant Science 23, 422-433.

Eichmann R, Schäfer P. 2015. Growth versus immunity - a redirection of the cell cycle? Current Opinion in Plant Biology 26, 106-112.

Emanuelle S, Hossain MI, Moller IE, et al. 2015. SnRK1 from Arabidopsis thaliana is an atypical AMPK. The Plant Journal $\mathbf{8 2 , 1 8 3 - 1 9 2 . ~}$

Fernandez O, Béthencourt L, Quero A, Sangwan RS, Clément C. 2010. Trehalose and plant stress responses: friend or foe? Trends in Plant Science 15, 409-417.

Filipe O, De Vleesschauwer D, Haeck A, Demeestere K, Höfte M. 2018. The energy sensor OsSnRK1a confers broad-spectrum disease resistance in rice. Scientific Reports 8, 3864.

Fonseca BD, Smith EM, Yelle N, Alain T, Bushell M, Pause A. 2014. The ever-evolving role of mTOR in translation. Seminars in Cell \& Developmental Biology 36, 102-112.

Fragoso S, Espíndola L, Páez-Valencia J, Gamboa A, Camacho Y, Martínez-Barajas E, Coello P. 2009. SnRK1 isoforms AKIN10 and AKIN11 are differentially regulated in Arabidopsis plants under phosphate starvation. Plant Physiology 149, 1906-1916.

Gao XQ, Liu CZ, Li DD, Zhao TT, Li F, Jia XN, Zhao XY, Zhang XS. 2016. The Arabidopsis KIN $\beta \gamma$ subunit of the SnRK1 complex regulates pollen hydration on the stigma by mediating the level of reactive oxygen species in pollen. PLoS Genetics 12, e1006228.

Gissot L, Polge C, Jossier M, Girin T, Bouly JP, Kreis M, Thomas M. 2006. AKINbetagamma contributes to SnRK1 heterotrimeric complexes and interacts with two proteins implicated in plant pathogen resistance through its KIS/GBD sequence. Plant Physiology 142, 931-944.

Glinski M, Weckwerth W. 2005. Differential multisite phosphorylation of the trehalose-6-phosphate synthase gene family in Arabidopsis thaliana: a mass spectrometry-based process for multiparallel peptide library phosphorylation analysis. Molecular \& Cellular Proteomics 4, 1614-1625.

Griffiths CA, Sagar R, Geng Y, et al. 2016. Chemical intervention in plant sugar signalling increases yield and resilience. Nature 540, 574-578.

Gururani MA, Venkatesh J, Tran LS. 2015. Regulation of photosynthesis during abiotic stress-induced photoinhibition. Molecular Plant 8, 1304-1320. 
Gwinn DM, Shackelford DB, Egan DF, Mihaylova MM, Mery A, Vasquez DS, Turk BE, Shaw RJ. 2008. AMPK phosphorylation of raptor mediates a metabolic checkpoint. Molecular Cell 30, 214-226.

Halford NG, Hey SJ. 2009. Snf1-related protein kinases (SnRKs) act within an intricate network that links metabolic and stress signalling in plants. Biochemical Journal 419, 247-259.

Hao L, Wang H, Sunter G, Bisaro DM. 2003. Geminivirus AL2 and L2 proteins interact with and inactivate SNF1 kinase. The Plant Cell 15, 1034-1048.

Harthill JE, Meek SE, Morrice N, Peggie MW, Borch J, Wong BH, Mackintosh C. 2006. Phosphorylation and 14-3-3 binding of Arabidopsis trehalose-phosphate synthase 5 in response to 2-deoxyglucose. The Plant Journal 47, 211-223.

Hrabak EM, Chan CW, Gribskov M, et al. 2003. The Arabidopsis CDPKSnRK superfamily of protein kinases. Plant Physiology 132, 666-680.

Hughes Hallett JE, Luo X, Capaldi AP. 2014. State transitions in the TORC1 signaling pathway and information processing in Saccharomyces cerevisiae. Genetics 198, 773-786.

Hughes Hallett JE, Luo X, Capaldi AP. 2015. Snf1/AMPK promotes the formation of Kog1/Raptor-bodies to increase the activation threshold of TORC1 in budding yeast. eLife 4, e09181.

Hulsmans S, Rodriguez M, De Coninck B, Rolland F. 2016. The SnRK1 energy sensor in plant biotic interactions. Trends in Plant Science 21, 648-661.

Huot B, Yao J, Montgomery BL, He SY. 2014. Growth-defense tradeoffs in plants: a balancing act to optimize fitness. Molecular Plant 7, 1267-1287.

Im JH, Cho YH, Kim GD, Kang GH, Hong JW, Yoo SD. 2014. Inverse modulation of the energy sensor Snf1-related protein kinase 1 on hypoxia adaptation and salt stress tolerance in Arabidopsis thaliana. Plant, Cell \& Environment 37, 2303-2312.

Inoki K, Li Y, Xu T, Guan KL. 2003. Rheb GTPase is a direct target of TSC2 GAP activity and regulates mTOR signaling. Genes \& Development 17, 1829-1834.

Jeong EY, Seo PJ, Woo JC, Park CM. 2015. AKIN10 delays flowering by inactivating IDD8 transcription factor through protein phosphorylation in Arabidopsis. BMC Plant Biology 15, 110.

Jones JD, Dangl JL. 2006. The plant immune system. Nature 444, 323-329.

Jossier M, Bouly JP, Meimoun P, Arjmand A, Lessard P, Hawley S, Grahame Hardie D, Thomas M. 2009. SnRK1 (SNF1-related kinase 1) has a central role in sugar and ABA signalling in Arabidopsis thaliana. The Plant Journal 59, 316-328.

Kleinow T, Bhalerao R, Breuer F, Umeda M, Salchert K, Koncz C. 2000. Functional identification of an Arabidopsis snf4 ortholog by screening for heterologous multicopy suppressors of snf4 deficiency in yeast. The Plant Journal 23, 115-122.

Kurumbail RG, Calabrese MF. 2016. Structure and regulation of AMPK. Experientia Supplementum (2012) 107, 3-22.

Li X, Cai W, Liu Y, Li H, Fu L, Liu Z, Xu L, Liu H, Xu T, Xiong Y. 2017 Differential TOR activation and cell proliferation in Arabidopsis root and shoot apexes. Proceedings of the National Academy of Sciences, USA 114, 2765-2770.

Li XF, Li YJ, An YH, Xiong LJ, Shao XH, Wang Y, Sun Y. 2009. AKINbeta1 is involved in the regulation of nitrogen metabolism and sugar signaling in Arabidopsis. Journal of Integrative Plant Biology 51, 513-520.

Liu L, Chung HY, Lacatus G, Baliji S, Ruan J, Sunter G. 2014. Altered expression of Arabidopsis genes in response to a multifunctional geminivirus pathogenicity protein. BMC Plant Biology 14, 302.

Liu Y, Bassham DC. 2010. TOR is a negative regulator of autophagy in Arabidopsis thaliana. PloS One 5, e11883.

Lovas A, Bimbó A, Szabó L, Bánfalvi Z. 2003. Antisense repression of StubGAL83 affects root and tuber development in potato. The Plant Journal 33, 139-147.

Lumbreras V, Alba MM, Kleinow T, Koncz C, Pagès M. 2001. Domain fusion between SNF1-related kinase subunits during plant evolution. EMBO Reports 2, 55-60.

Lunn JE, Delorge I, Figueroa CM, Van Dijck P, Stitt M. 2014. Trehalose metabolism in plants. The Plant Journal 79, 544-567.
MacKintosh C. 1992. Regulation of spinach-leaf nitrate reductase by reversible phosphorylation. Biochimica et Biophysica Acta 1137, 121-126.

Mahfouz MM, Kim S, Delauney AJ, Verma DP. 2006. Arabidopsis TARGET OF RAPAMYCIN interacts with RAPTOR, which regulates the activity of S6 kinase in response to osmotic stress signals. The Plant Cell 18, 477-490.

Mair A, Pedrotti L, Wurzinger B, et al. 2015. SnRK1-triggered switch of bZIP63 dimerization mediates the low-energy response in plants. eLife 4, e05828.

Malinovsky FG, Thomsen MF, Nintemann SJ, Jagd LM, Bourgine B, Burow M, Kliebenstein DJ. 2017. An evolutionarily young defense metabolite influences the root growth of plants via the ancient TOR signaling pathway. eLife 6, e29353.

Margalha L, Valerio C, Baena-González E. 2016. Plant SnRK1 kinases: structure, regulation, and function. Experientia Supplementum (2012) 107, 403-438.

Martín-Fontecha ES, Tarancón C, Cubas P. 2018. To grow or not to grow, a power-saving program induced in dormant buds. Current Opinion in Plant Biology 41, 102-109.

McBride A, Ghilagaber S, Nikolaev A, Hardie DG. 2009. The glycogenbinding domain on the AMPK beta subunit allows the kinase to act as a glycogen sensor. Cell Metabolism 9, 23-34.

McMichael RW Jr, Kochansky J, Klein RR, Huber SC. 1995 Characterization of the substrate specificity of sucrose-phosphate synthase protein kinase. Archives of Biochemistry and Biophysics 321, 71-75.

Menand B, Desnos T, Nussaume L, Berger F, Bouchez D, Meyer C, Robaglia C. 2002. Expression and disruption of the Arabidopsis TOR (target of rapamycin) gene. Proceedings of the National Academy of Sciences, USA 99, 6422-6427.

Meteignier LV, El Oirdi M, Cohen M, Barff T, Matteau D, Lucier JF, Rodrigue S, Jacques PE, Yoshioka K, Moffett P. 2017. Translatome analysis of an NB-LRR immune response identifies important contributors to plant immunity in Arabidopsis. Journal of Experimental Botany 68, 2333-2344.

Mittler R. 2006. Abiotic stress, the field environment and stress combination. Trends in Plant Science 11, 15-19.

Mohannath G, Jackel JN, Lee YH, Buchmann RC, Wang H, Patil V, Adams AK, Bisaro DM. 2014. A complex containing SNF1-related kinase (SnRK1) and adenosine kinase in Arabidopsis. PLoS One 9, e87592.

Moreau M, Azzopardi M, Clément G, et al. 2012. Mutations in the Arabidopsis homolog of LST8/GßL, a partner of the target of Rapamycin kinase, impair plant growth, flowering, and metabolic adaptation to long days. The Plant Cell 24, 463-481.

Naseem M, Dandekar T. 2012. The role of auxin-cytokinin antagonism in plant-pathogen interactions. PLoS Pathogens 8, e1003026.

Nietzsche M, Guerra T, Alseekh S, Wiermer M, Sonnewald S, Fernie AR, Börnke F. 2018. STOREKEEPER RELATED1/G-element binding protein (STKR1) interacts with protein kinase SnRK1. Plant Physiology 176, 1773-1792.

Nietzsche M, Landgraf R, Tohge T, Börnke F. 2016. A protein-protein interaction network linking the energy-sensor kinase SnRK1 to multiple signaling pathways in Arabidopsis thaliana. Current Plant Biology 5, 36-44.

Nukarinen E, Nägele T, Pedrotti L, et al. 2016. Quantitative phosphoproteomics reveals the role of the AMPK plant ortholog SnRK1 as a metabolic master regulator under energy deprivation. Scientific Reports 6, 31697.

Nunes C, O'Hara LE, Primavesi LF, Delatte TL, Schluepmann H, Somsen GW, Silva AB, Fevereiro PS, Wingler A, Paul MJ. 2013a. The trehalose 6-phosphate/SnRK1 signaling pathway primes growth recovery following relief of sink limitation. Plant Physiology 162, 1720-1732.

Nunes C, Primavesi LF, Patel MK, Martinez-Barajas E, Powers SJ, Sagar R, Fevereiro PS, Davis BG, Paul MJ. 2013b. Inhibition of SnRK1 by metabolites: tissue-dependent effects and cooperative inhibition by glucose 1-phosphate in combination with trehalose 6-phosphate. Plant Physiology and Biochemistry 63, 89-98.

Ouibrahim L, Rubio AG, Moretti A, Montané MH, Menand B, Meyer C, Robaglia C, Caranta C. 2015. Potyviruses differ in their requirement for TOR signalling. Journal of General Virology 96, 2898-2903.

Paul MJ, Gonzalez-Uriarte A, Griffiths CA, Hassani-Pak K. 2018. The role of trehalose 6-phosphate in crop yield and resilience. Plant Physiology $177,12-23$. 
Perochon A, Jianguang J, Kahla A, Arunachalam C, Scofield SR, Bowden S, Wallington E, Doohan FM. 2015. TaFROG encodes a pooideae orphan protein that interacts with SnRK1 and enhances resistance to the mycotoxigenic fungus Fusarium graminearum. Plant Physiology 169, 2895-2906

Pfeiffer A, Janocha D, Dong Y, et al. 2016. Integration of light and metabolic signals for stem cell activation at the shoot apical meristem. eLife $\mathbf{5}$, e17023.

Piattoni CV, Bustos DM, Guerrero SA, Iglesias AÁ. 2011. Nonphosphorylating glyceraldehyde-3-phosphate dehydrogenase is phosphorylated in wheat endosperm at serine-404 by an SNF1-related protein kinase allosterically inhibited by ribose-5-phosphate. Plant Physiology 156, 1337-1350.

Popa C, Li L, Gil S, Tatjer L, Hashii K, Tabuchi M, Coll NS, Ariño J, Valls M. 2016. The effector AWR5 from the plant pathogen Ralstonia solanacearum is an inhibitor of the TOR signalling pathway. Scientific Reports 6, 27058

Pu Y, Luo X, Bassham DC. 2017a. TOR-dependent and -independent pathways regulate autophagy in Arabidopsis thaliana. Frontiers in Plant Science 8, 1204

Pu Y, Soto-Burgos J, Bassham DC. 2017b. Regulation of autophagy through SnRK1 and TOR signaling pathways. Plant Signaling \& Behavior 12, e1395128.

Radchuk R, Emery RJ, Weier D, Vigeolas H, Geigenberger P, Lunn JE, Feil R, Weschke W, Weber H. 2010. Sucrose non-fermenting kinase 1 (SnRK1) coordinates metabolic and hormonal signals during pea cotyledon growth and differentiation. The Plant Journal 61, 324-338.

Radchuk R, Radchuk V, Weschke W, Borisjuk L, Weber H. 2006. Repressing the expression of the SUCROSE NONFERMENTING-1RELATED PROTEIN KINASE gene in pea embryo causes pleiotropic defects of maturation similar to an abscisic acid-insensitive phenotype. Plant Physiology 140, 263-278.

Ramon M, Ruelens P, Li Y, Sheen J, Geuten K, Rolland F. 2013. The hybrid four-CBS-domain KIN $\beta \gamma$ subunit functions as the canonical $\gamma$ subunit of the plant energy sensor SnRK1. The Plant Journal 75, 11-25.

Ren M, Qiu S, Venglat P, Xiang D, Feng L, Selvaraj G, Datla R. 2011. Target of rapamycin regulates development and ribosomal RNA expression through kinase domain in Arabidopsis. Plant Physiology 155, 1367-1382.

Ren M, Venglat P, Qiu S, et al. 2012. Target of rapamycin signaling regulates metabolism, growth, and life span in Arabidopsis. The Plant Cell 24, 4850-4874.

Robertlee J, Kobayashi K, Suzuki M, Muranaka T. 2017. AKIN10, a representative Arabidopsis SNF1-related protein kinase 1 (SnRK1), phosphorylates and downregulates plant HMG-CoA reductase. FEBS Letters 591, 1159-1166.

Rodrigues A, Adamo M, Crozet P, et al. 2013. ABI1 and PP2CA phosphatases are negative regulators of Snf1-related protein kinase1 signaling in Arabidopsis. The Plant Cell 25, 3871-3884.

Rosenberger CL, Chen J. 2018. To grow or not to grow: TOR and SnRK2 coordinate growth and stress response in Arabidopsis. Molecular Cell 69, $3-4$.

Roustan V, Jain A, Teige M, Ebersberger I, Weckwerth W. 2016. An evolutionary perspective of AMPK-TOR signaling in the three domains of life. Journal of Experimental Botany 67, 3897-3907.

Salem MA, Li Y, Bajdzienko K, Fisahn J, Watanabe M, Hoefgen R, Schöttler MA, Giavalisco P. 2018. RAPTOR controls developmental growth transitions by altering the hormonal and metabolic balance. Plant Physiology 177, 565-593.

Salem MA, Li Y, Wiszniewski A, Giavalisco P. 2017. Regulatoryassociated protein of TOR (RAPTOR) alters the hormonal and metabolic composition of Arabidopsis seeds, controlling seed morphology, viability and germination potential. The Plant Journal 92, 525-545.

Sanz P, Viana R, Garcia-Gimeno MA. 2016. AMPK in yeast: the SNF1 (Sucrose Non-fermenting 1) protein kinase complex. Experientia Supplementum (2012) 107, 353-374.

Saxton RA, Sabatini DM. 2017. mTOR signaling in growth, metabolism, and disease. Cell 169, 361-371.

Schepetilnikov M, Dimitrova M, Mancera-Martínez E, Geldreich A, Keller M, Ryabova LA. 2013. TOR and S6K1 promote translation reinitiation of $\mathrm{UORF}$-containing mRNAs via phosphorylation of elF3h. The EMBO Journal 32, 1087-1102.

Schepetilnikov M, Kobayashi K, Geldreich A, Caranta C, Robaglia C, Keller M, Ryabova LA. 2011. Viral factor TAV recruits TOR/S6K1 signalling to activate reinitiation after long ORF translation. The EMBO Journal $\mathbf{3 0}$, 1343-1356.

Schepetilnikov M, Makarian J, Srour O, Geldreich A, Yang Z, Chicher J, Hammann P, Ryabova LA. 2017. GTPase ROP2 binds and promotes activation of target of rapamycin, TOR, in response to auxin. The EMBO Journal 36, 886-903.

Schepetilnikov M, Ryabova LA. 2018. Recent discoveries on the role of TOR (Target of Rapamycin) signaling in translation in plants. Plant Physiology 176, 1095-1105

Schluepmann H, Paul M. 2009. Trehalose metabolites in Arabidopsiselusive, active and central. The Arabidopsis Book 7, e0122.

Schuck S, Baldwin IT, Bonaventure G. 2013. HSPRO acts via SnRK1mediated signaling in the regulation of Nicotiana attenuata seedling growth promoted by Piriformospora indica. Plant Signaling \& Behavior 8, e23537.

Schuck S, Camehl I, Gilardoni PA, Oelmueller R, Baldwin IT, Bonaventure G. 2012. HSPRO controls early Nicotiana attenuata seedling growth during interaction with the fungus Piriformospora indica. Plant Physiology 160, 929-943.

Schwachtje J, Minchin PE, Jahnke S, van Dongen JT, Schittko U, Baldwin IT. 2006. SNF1-related kinases allow plants to tolerate herbivory by allocating carbon to roots. Proceedings of the National Academy of Sciences, USA 103, 12935-12940.

Seo YS, Chern M, Bartley LE, et al. 2011. Towards establishment of a rice stress response interactome. PLoS Genetics 7, e1002020.

Sheen J. 2014. Master regulators in plant glucose signaling networks. Journal of Plant Biology 57, 67-79.

Shen Q, Bao M, Zhou X. 2012. A plant kinase plays roles in defense response against geminivirus by phosphorylation of a viral pathogenesis protein. Plant Signaling \& Behavior 7, 888-892.

Shen Q, Liu Z, Song F, Xie Q, Hanley-Bowdoin L, Zhou X. 2011. Tomato SISnRK1 protein interacts with and phosphorylates $\beta C 1$, a pathogenesis protein encoded by a geminivirus $\beta$-satellite. Plant Physiology $\mathbf{1 5 7}$, 1394-1406.

Shen W, Bobay BG, Greeley LA, Reyes MI, Rajabu CA, Blackburn RK, Dallas MB, Goshe MB, Ascencio-lbáñez JT, Hanley-Bowdoin L. 2018. Sucrose nonfermenting 1-related protein kinase 1 phosphorylates a geminivirus rep protein to impair viral replication and infection. Plant Physiology 178, 372-389.

Shen W, Dallas MB, Goshe MB, Hanley-Bowdoin L. 2014. SnRK1 phosphorylation of AL2 delays Cabbage leaf curl virus infection in Arabidopsis. Journal of Virology 88, 10598-10612.

Shen W, Hanley-Bowdoin L. 2006. Geminivirus infection up-regulates the expression of two Arabidopsis protein kinases related to yeast SNF1- and mammalian AMPK-activating kinases. Plant Physiology 142, 1642-1655.

Shen W, Reyes MI, Hanley-Bowdoin L. 2009. Arabidopsis protein kinases GRIK1 and GRIK2 specifically activate SnRK1 by phosphorylating its activation loop. Plant Physiology 150, 996-1005.

Shi L, Wu Y, Sheen J. 2018. TOR signaling in plants: conservation and innovation. Development 145, dev160887.

Son S, Oh CJ, An CS. 2014. Arabidopsis thaliana remorins interact with SnRK1 and play a role in susceptibility to beet curly top virus and beet severe curly top virus. The Plant Pathology Journal 30, 269-278.

Song Y, Zhang H, You H, et al. 2019. Identification of novel interactors and potential phosphorylation substrates of GsSnRK1 from wild soybean (Glycine soja). Plant, Cell \& Environment 42, 145-157.

Soto-Burgos J, Bassham DC. 2017. SnRK1 activates autophagy via the TOR signaling pathway in Arabidopsis thaliana. PLoS One 12, e0182591.

Soto-Burgos J, Zhuang X, Jiang L, Bassham DC. 2018. Dynamics of autophagosome formation. Plant Physiology 176, 219-229.

Sugden C, Crawford RM, Halford NG, Hardie DG. 1999a. Regulation of spinach SNF1-related (SnRK1) kinases by protein kinases and phosphatases is associated with phosphorylation of the T loop and is regulated by $5^{\prime}$-AMP. The Plant Journal 19, 433-439. 
Sugden C, Donaghy PG, Halford NG, Hardie DG. 1999b. Two SNF1 related protein kinases from spinach leaf phosphorylate and inactivate 3-hydroxy-3-methylglutaryl-coenzyme A reductase, nitrate reductase, and sucrose phosphate synthase in vitro. Plant Physiology 120, 257-274.

Sunter G, Sunter JL, Bisaro DM. 2001. Plants expressing tomato golden mosaic virus AL2 or beet curly top virus $L 2$ transgenes show enhanced susceptibility to infection by DNA and RNA viruses. Virology 285, 59-70.

Szczesny R, Büttner D, Escolar L, Schulze S, Seiferth A, Bonas U. 2010. Suppression of the AvrBs1-specific hypersensitive response by the YopJ effector homolog AvrBsT from Xanthomonas depends on a SNF1related kinase. New Phytologist 187, 1058-1074.

Tarancón C, González-Grandío E, Oliveros JC, Nicolas M, Cubas P. 2017. A conserved carbon starvation response underlies bud dormancy in woody and herbaceous species. Frontiers in Plant Science 8, 788.

Tomé F, Nägele T, Adamo M, et al. 2014. The low energy signaling network. Frontiers in Plant Science 5, 353.

Toroser D, Plaut Z, Huber SC. 2000. Regulation of a plant SNF1-related protein kinase by glucose-6-phosphate. Plant Physiology 123, 403-412.

Tsai AY, Gazzarrini S. 2012. AKIN10 and FUSCA3 interact to control lateral organ development and phase transitions in Arabidopsis. The Plant Journal 69, 809-821.

Üstün S, Hafrén A, Hofius D. 2017. Autophagy as a mediator of life and death in plants. Current Opinion in Plant Biology 40, 122-130.

van Dam TJ, Zwartkruis FJ, Bos JL, Snel B. 2011. Evolution of the TOR pathway. Journal of Molecular Evolution 73, 209-220.

Wang H, Hao L, Shung CY, Sunter G, Bisaro DM. 2003. Adenosine kinase is inactivated by geminivirus AL2 and L2 proteins. The Plant Cell 15, 3020-3032.

Wang L, Li H, Zhao C, et al. 2017. The inhibition of protein translation mediated by AtGCN1 is essential for cold tolerance in Arabidopsis thaliana. Plant, Cell \& Environment 40, 56-68.

Wang P, Zhao Y, Li Z, et al. 2018. Reciprocal regulation of the TOR kinase and ABA receptor balances plant growth and stress response. Molecular Cell 69, 100-112.e6.

Wang XY, Li DZ, Li Q, Ma YQ, Yao JW, Huang X, Xu ZQ. 2016. Metabolomic analysis reveals the relationship between AZI1 and sugar signaling in systemic acquired resistance of Arabidopsis. Plant Physiology and Biochemistry 107, 273-287.

Weiste C, Pedrotti L, Selvanayagam J, Muralidhara P, Fröschel C, Novák O, Ljung K, Hanson J, Dröge-Laser W. 2017. The Arabidopsis bZIP11 transcription factor links low-energy signalling to auxin-mediated control of primary root growth. PLoS Genetics 13, e1006607.
Wiatrowski HA, Van Denderen BJ, Berkey CD, Kemp BE, Stapleton D, Carlson M. 2004. Mutations in the gal83 glycogen-binding domain activate the snf1/gal83 kinase pathway by a glycogen-independent mechanism. Molecular and Cellular Biology 24, 352-361.

Wilson WA, Hawley SA, Hardie DG. 1996. Glucose repression/derepression in budding yeast: SNF1 protein kinase is activated by phosphorylation under derepressing conditions, and this correlates with a high AMP:ATP ratio. Current Biology 6, 1426-1434.

Winter D, Vinegar B, Nahal H, Ammar R, Wilson GV, Provart NJ. 2007. An 'Electronic Fluorescent Pictograph' browser for exploring and analyzing large-scale biological data sets. PLoS One 2, e718.

Wurzinger B, Mair A, Fischer-Schrader K, Nukarinen E, Roustan V, Weckwerth W, Teige M. 2017. Redox state-dependent modulation of plant SnRK1 kinase activity differs from AMPK regulation in animals. FEBS Letters 591, 3625-3636.

Xiong Y, McCormack M, Li L, Hall Q, Xiang C, Sheen J. 2013. GlucoseTOR signalling reprograms the transcriptome and activates meristems. Nature 496, 181-186.

Xiong Y, Sheen J. 2012. Rapamycin and glucose-target of rapamycin (TOR) protein signaling in plants. Journal of Biological Chemistry 287, 2836-2842.

Xiong Y, Sheen J. 2015. Novel links in the plant TOR kinase signaling network. Current Opinion in Plant Biology 28, 83-91.

Zhai Z, Keereetaweep J, Liu H, Feil R, Lunn JE, Shanklin J. 2018. Trehalose 6 -phosphate positively regulates fatty acid synthesis by stabilizing WRINKLED1. The Plant Cell 30, 2616-2627.

Zhang Y, Andralojc PJ, Hey SJ, Primavesi LF, Specht M, Koehler J, Parry MAJ, Halford NG. 2008. Arabidopsis sucrose non-fermenting-1-related protein kinase-1 and calcium-dependent protein kinase phosphorylate conserved target sites in ABA response element binding proteins. Annals of Applied Biology 153, 401-409.

Zhang Y, Primavesi LF, Jhurreea D, Andralojc PJ, Mitchell RA, Powers SJ, Schluepmann H, Delatte T, Wingler A, Paul MJ. 2009. Inhibition of SNF1-related protein kinase1 activity and regulation of metabolic pathways by trehalose-6-phosphate. Plant Physiology 149, 1860-1871.

Zhang Z, Zhu JY, Roh J, Marchive C, Kim SK, Meyer C, Sun Y, Wang W, Wang ZY. 2016. TOR signaling promotes accumulation of BZR1 to balance growth with carbon availability in Arabidopsis. Current Biology 26, 1854-1860.

Zvereva AS, Golyaev V, Turco S, Gubaeva EG, Rajeswaran R, Schepetilnikov MV, Srour O, Ryabova LA, Boller T, Pooggin MM. 2016. Viral protein suppresses oxidative burst and salicylic acid-dependent autophagy and facilitates bacterial growth on virus-infected plants. New Phytologist 211, 1020-1034. 